\title{
Occurrence of endocrine disrupting compounds in mariculture sediment of Pulau Kukup, Johor, Malaysia
}

\begin{abstract}
Endocrine-disrupting compounds (EDCs) such as hormones, pesticides, phenolic compounds, and pharmaceuticals compounds can cause adverse effects on humans, animals, and other living organisms. One of the largest mariculture areas situated in Pulau Kukup, Johor, Malaysia, is actively involved in exporting marine fish to other countries worldwide. This paper aims to provide baseline data on the level of EDC pollutants found in mariculture sediments in Malaysia since no reports have investigated this issue. Calculated samples recovered are between 50.39 and $129.10 \%$ at $100 \mathrm{ng} / \mathrm{g}$ spiking level. The highest concentration in the sediment samples was bisphenol A (0.072-0.389 ng/g dry weight) followed by diethylstilbestrol $(<0.208-0.331 \mathrm{ng} / \mathrm{g}$ dry weight $)$ and propranolol $(<0.250-0.275 \mathrm{ng} / \mathrm{g}$ dry weight). Even though the concentrations of the targeted compounds obtained were low, their effects could become more evident longer term, which raises not only environmental health concerns but the potential risk to humans.
\end{abstract}

Keyword: Endocrine disrupting compounds (EDCs); Sediment; Soxhlet extraction; Pulau Kukup, Malaysia; Mariculture zone 